\title{
Rhenium Metal and Rhenium Nitride Thin Films Grown by Atomic Layer Deposition
}

\section{Hämäläinen, Jani}

2018-10-26

Hämäläinen , J , Mizohata , K, Meinander , K, Mattinen , M , Vehkamäki , M , Räisänen , J , Ritala , M \& Leskelä , M 2018 , ' Rhenium Metal and Rhenium Nitride Thin Films Grown by Atomic Layer Deposition ' , Angewandte Chemie (International Edition), vol. 57 , no. 44 , pp. 14538-14542 . https://doi.org/10.1002/anie.201806985

http://hdl.handle.net/10138/325623

https://doi.org/10.1002/anie.201806985

unspecified

acceptedVersion

Downloaded from Helda, University of Helsinki institutional repository.

This is an electronic reprint of the original article.

This reprint may differ from the original in pagination and typographic detail.

Please cite the original version. 


\title{
Rhenium Metal and Rhenium Nitride Thin Films Grown by Atomic Layer Deposition
}

\author{
Jani Hämäläinen, ${ }^{* a]}$ Kenichiro Mizohata, ${ }^{[b]}$ Kristoffer Meinander, ${ }^{[b]}$ Miika Mattinen, ${ }^{[a]}$ Marko \\ Vehkamäki, ${ }^{[a]}$ Jyrki Räisänen, ${ }^{[b]}$ Mikko Ritala, ${ }^{[a]}$ and Markku Leskelä ${ }^{[a]}$
}

\begin{abstract}
Rhenium is both a refractory metal and a noble metal that has attractive properties for various applications. Still, synthesis and applications of rhenium thin films have been limited. We introduce here the growth of both rhenium metal and rhenium nitride thin films by the technologically important atomic layer deposition (ALD) method over a wide deposition temperature range using fast, simple, and robust surface reactions between rhenium pentachloride and ammonia. Films are grown and characterized for compositions, surface morphologies and roughnesses, crystallinities, and resistivities. Conductive rhenium subnitride films of tunable composition are obtained at deposition temperatures between 275 and $375{ }^{\circ} \mathrm{C}$, whereas pure rhenium metal films grow at $400{ }^{\circ} \mathrm{C}$ and above. Already a $3 \mathrm{~nm}$ thick rhenium film is continuous and has a low resistivity of about $90 \mu \Omega \mathrm{cm}$ showing potential for applications where also other noble metals and refractory metals have been considered.
\end{abstract}

The late discovery, complicated extraction from nature, and scarcity of the element have been limiting research and applications of rhenium. Still, rhenium is crucial in super-alloys for jet engines and in catalysis. As an example, Re-Pt catalysts are vital in making lead-free, high-octane petrol. ${ }^{[1]}$ Rhenium has also been applied for ammonia synthesis ${ }^{[} 2,3$ ] and hydrodenitrogenation, ${ }^{[4]}$ and it is a potential photoelectrocatalyst for reduction of nitrate ions. ${ }^{[5]}$ Rhenium has been suggested for hydrogen evolution reaction (HER) as well but with contradictory results. ${ }^{[6]}$ Notably, Re should perform similarly as $\mathrm{Co}$ and $\mathrm{Ni}$ in $\mathrm{HER}$, but rhenium oxides are even better and as good as $\mathrm{Pt},{ }^{[6]}$ which is considered to be the most effective HER catalyst. One potential application is the use of rhenium as a liner material in gun tubes as Re coatings outperformed the commonly applied hard chrome plating in vented bomb combustor tests. ${ }^{[7]}$ Microwave resonators have been made using epitaxial $R e$ on sapphire. ${ }^{[8]} \mathrm{Re}$ and rhenium nitride barrier layers against $\mathrm{Cu}$ diffusion have been studied and found to inhibit $\mathrm{Cu} / \mathrm{Si}$ interdiffusion and silicide formation effectively. ${ }^{[9,10]}$ As rhenium has been used for preparation of $\mathrm{Re} / \mathrm{Al}-\mathrm{Al}_{2} \mathrm{O}_{3} / \mathrm{Re}$ Josephson

[a] Dr. J. Hämäläinen, M. Mattinen, Dr. M. Vehkamäki, Prof. M. Ritala Prof. M. Leskelä

Department of Chemistry

University of Helsinki

P.O. Box 55, FI-00014 Helsinki, Finland

E-mail: jani.hamalainen@helsinki.fi

[b] Dr. K. Mizohata, Dr. K. Meinander, Prof. J. Räisänen Division of Materials Physics, Department of Physics University of Helsinki

P.O. Box 64, FI-00014 Helsinki, Finland

Supporting information for this article is given via a link at the end of the document. tunnel junctions, ${ }^{[11]}$ it could be of interest in superconducting quantum computing and quantum information applications too. Furthermore, $7 \mathrm{~nm}$ thick Re gate contacts in $\mathrm{Re} / \mathrm{HfO}_{2} / \mathrm{Si}(100)$ stacked structures have been previously evaluated ${ }^{[12]}$ to prevent oxygen diffusion up to $500^{\circ} \mathrm{C}$ in oxygen-containing atmosphere. For the electrode applications in metal-oxide-semiconductor fieldeffect transistors (MOSFETs) and various capacitors Re could be an interesting alternative to ruthenium as they have nearly identical work functions ( $R e 4.72 \mathrm{eV}$ and $\mathrm{Ru} 4.71 \mathrm{eV}$ ). Importantly, Re costs currently substantially less and its annual production is about three times higher than that of $\mathrm{Ru}$.

Rhenium has a rich nitride chemistry. Both crystalline subnitrides and nitrides of rhenium such as $\operatorname{Re}_{3} \mathrm{~N}, \mathrm{Re}_{2} \mathrm{~N}, \mathrm{Re}_{3} \mathrm{~N}_{2}, \mathrm{ReN}_{2}, \mathrm{ReN}_{3}$, and $\mathrm{ReN}_{4}$ have been noted to exist. ${ }^{[13]}$ Rhenium nitrides can be used in several applications, although these have been limited due to the scarcity of the materials. Similar to Re metal, also $\mathrm{Re}_{3} \mathrm{~N}$ has been used as a catalyst for ammonia synthesis, ${ }^{[2,3]}$ and it is active also for hydrodenitrogenation. ${ }^{[4]}$ Both $\mathrm{Re}_{3} \mathrm{~N}$ and $\mathrm{Re}_{2} \mathrm{~N}$ are ultrastiff and hard materials, and in contrast to most other hard materials they also have good electronic mobility. ${ }^{[14]}$ Thus, they could be considered as hard conductors for extreme conditions.

Although rhenium is rare and can be difficult to synthesize, various methods have still been employed to grow particles, powders, thin films, and coatings. These techniques include chemical vapor deposition (CVD),$^{[7,12]}$ chemical vapor infiltration $(\mathrm{CVI}),{ }^{[15]}$ pulsed laser evaporation (PLE), ${ }^{[16]}$ electron-beam evaporation, ${ }^{[12]}$ electrodeposition, ${ }^{[5]}$ molecular beam epitaxy $(\mathrm{MBE}),{ }^{[8]}$ and magnetron sputtering. ${ }^{[17]}$ Even more limited has been the preparation of rhenium nitrides which have been synthesized by sputtering, ${ }^{[18,19]}$ ion implantation, ${ }^{[20]}$ pulsed laser deposition, ${ }^{[21]}$ and high-pressure solid-state metathesis. ${ }^{[22,23]}$ There is thus still room for introducing new methods for preparing these intriguing refractory/noble metal materials to make them more widely available for various applications using highly controllable methods with moderate deposition conditions.

Atomic layer deposition (ALD) ${ }^{[24,25]}$ has become a crucial industrial technique to deposit thin films and nanoparticles, especially in the semiconductor industry. ALD is similar to CVD as thin films are deposited chemically from a vapor phase, but inherent to ALD is the alternate supply of the precursors and thus the films grow in uniform and conformal manner over large and complex substrates with precise control on film thickness and excellent repeatability. These properties make ALD an unrivaled thin film deposition method for microelectronics and nanotechnology where the dimensions are continuously shrinking and device designs becoming more complex and three-dimensional. This has led into 
a growing academic and commercial interest in ALD, and an industrially driven necessity to develop new ALD processes and materials. The inherent properties of ALD also provide straightforward scalability in terms of number and size of substrates which narrows the gap between fundamental and applied research, and industry. Fundamental research on ALD process development is still needed to provide new materials, perspectives, and tools for the high-technology applications of the future.

Here we report the deposition of rhenium and rhenium nitride $\left(\mathrm{ReN}_{\mathrm{x}}\right)$ thin films for the first time by ALD using ammonia as the co-reactant and the same $\mathrm{ReCl}_{5}$ precursor as recently exploited ${ }^{[26]}$ for the $\mathrm{ReS}_{2} \mathrm{ALD}$. The Re metal growth relies on fully reductive chemistry in contrast to typical noble metal ALD. Simple and robust precursors are used and the growth proceeds via fast saturative surface reactions. Deposition of low resistivity rhenium nitride is also demonstrated by lowering the deposition temperature. These $\mathrm{Re}$ and $\mathrm{ReN} \mathrm{N}_{\mathrm{x}}$ ALD processes that do not use oxidizing or oxygen-containing precursors are very attractive for applications where the oxidation of the underlying material must be avoided. Volatile metal halides have excelled in many industrial applications of ALD ranging from electroluminescent displays to gate oxides in microprocessors because of their hightemperature stability, sufficient volatility, and small size of the ligands, i.e. high metal content in the compound. That in mind, we report here another simple ALD metal halide process that can be used to deposit thin, conductive films of either metal or metal nitride of tunable composition.

$\mathrm{Re}$ and $\mathrm{ReN}_{\mathrm{x}}$ thin films were deposited from $\mathrm{ReCl}_{5}(99.9 \%)$ and $\mathrm{NH}_{3}(99.9999 \%)$ in a commercial ALD reactor operated under a reduced nitrogen pressure (5-10 mbar). The films were grown on about $5-10 \mathrm{~nm}$ thick $\mathrm{Al}_{2} \mathrm{O}_{3}$ films on top of native oxide covered silicon (100) substrates $\left(5 \times 5 \mathrm{~cm}^{2}\right)$. The solid $\mathrm{ReCl}_{5}$ precursor was sublimed from an open boat inside the reactor at $110^{\circ} \mathrm{C}$ and pulsed with inert gas valving. The flow rate of $\mathrm{NH}_{3}$ was $5 \mathrm{sccm}$ unless otherwise stated. Additional experimental details can be found from the Supporting information.

Thin film growth is successfully obtained pulsing $\mathrm{ReCl}_{5}$ and $\mathrm{NH}_{3}$ alternately at deposition temperatures above $250{ }^{\circ} \mathrm{C}$ (Figure 1). For crystalline rhenium nitride films deposited at 325 and $375^{\circ} \mathrm{C}$ (Figure $1 b$ ) the growth rate is $0.4-0.5 \AA /$ cycle as determined by $x$ ray reflectivity (XRR) measurements (Figure 1a). Films deposited at $400{ }^{\circ} \mathrm{C}$ and above are metallic Re instead of $\operatorname{ReN}_{x}$ (Figure $1 \mathrm{~b}$ ) according to the grazing incidence $x$-ray diffraction (GIXRD) patterns and the growth rate decreases to $0.3 \AA$ /cycle (Figure 1a). The film morphology seen in field emission scanning electron microscope (FESEM) images changes distinctively between 375 and $400{ }^{\circ} \mathrm{C}$, i.e. at the same time when the film composition changes from $\mathrm{ReN}_{\mathrm{x}}$ to $\mathrm{Re}$ (Figure 1c). The film roughness remains about 2-3 nm for the films grown using 1000 cycles as measured by atomic force microscope (AFM).

Reduction of $\mathrm{ReN}$ to $\mathrm{Re}$ at $400^{\circ} \mathrm{C}$ and above can be explained by the instability of rhenium nitrides, even if ammonia is used here as a co-reactant. Interestingly Alexander et al. ${ }^{[27]}$ have shown $\mathrm{Re}_{3} \mathrm{~N}$ to lose close to $90 \%$ of its nitrogen under $\mathrm{H}_{2}$ atmosphere at $350{ }^{\circ} \mathrm{C}$. That is close to the deposition temperature $\left(400{ }^{\circ} \mathrm{C}\right)$ where the ALD growth of Re begins instead of $\operatorname{ReN}_{x}$ (Figure $1 b$ ).
The depositions at 450 and $500^{\circ} \mathrm{C}$ resulted in defective Re films and the flaking of the film was most dominant at $500^{\circ} \mathrm{C}$. The film flaking at the highest deposition temperatures could be likely avoided by the proper choice of the starting surface. It is noted that despite the flaking the Re films grown at 450 and $500^{\circ} \mathrm{C}$ have relatively low film resistivities (Figure 1a) and impurity contents (to be discussed below). a)

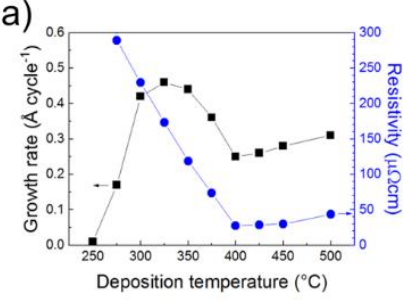

b)

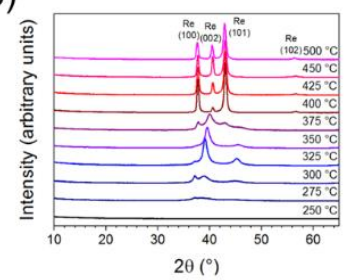

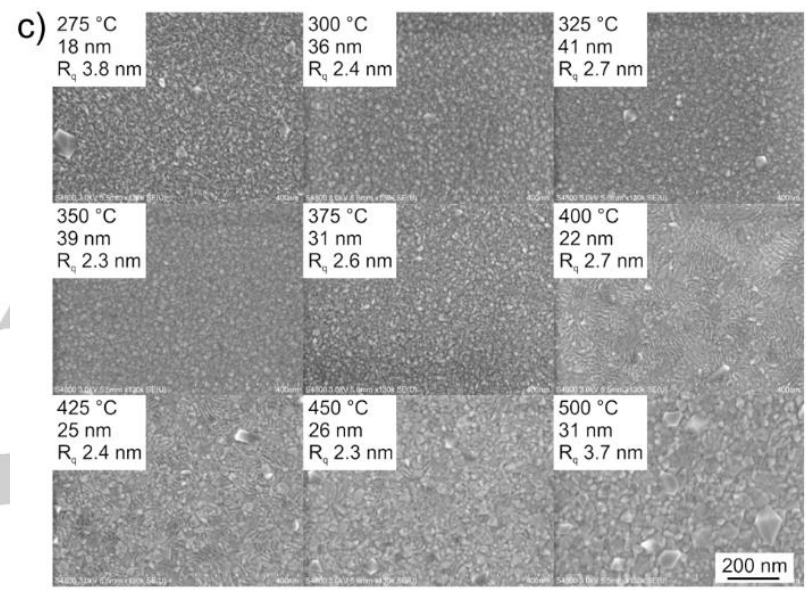

Figure 1. Re and $\mathrm{ReN}_{x}$ films grown on $\mathrm{Al}_{2} \mathrm{O}_{3}$ films at various deposition temperatures. a) Growth rates (XRR) and resistivities, b) GIXRD patterns, and c) FESEM images with deposition temperatures, film thicknesses (EDX; density corrected by XRR), and surface roughnesses ( $\left.R_{\mathrm{q}}, A F M\right)$. The pulse and purge lengths were $2 \mathrm{~s}$ and $1 \mathrm{~s}$, respectively. The total number of deposition cycles was 1000 .

As analyzed with time-of-flight elastic recoil detection analysis (TOF-ERDA) the deposited $\operatorname{Re}\left(\geq 400^{\circ} \mathrm{C}\right)$ and $\operatorname{ReN}_{\mathrm{x}}\left(<400^{\circ} \mathrm{C}\right)$ thin films are pure (Table S2). The total impurity content of $\mathrm{Cl}, \mathrm{N}$, and $\mathrm{H}$ in the Re thin films grown at 400 and $425^{\circ} \mathrm{C}$ is only about 2 at. \%. As the nitrogen content is 1 at. \% in all the Re metal films deposited below $500{ }^{\circ} \mathrm{C}$ and the films are phase-pure metal in GIXRD (Figure 1b), complete reduction to Re can be concluded. It should be emphasized that this reductive metal ALD process uses one of the simplest metal ALD chemistries in terms of the number of elements and the size of the ligands, i.e. only $\mathrm{Re}, \mathrm{Cl}$, $\mathrm{N}$, and $\mathrm{H}$ are involved in reactions between $\mathrm{ReCl}_{5}$ and $\mathrm{NH}_{3}$ under reduced $\mathrm{N}_{2}$ pressure. The $\mathrm{N} / \mathrm{Re}$ ratios $(\sim 0.2-0.5)$ of the rhenium nitride films grown between 275 and $350^{\circ} \mathrm{C}$ are close to the $\mathrm{Re}_{3} \mathrm{~N}$ (0.33) and $\operatorname{Re}_{2} \mathrm{~N}(0.50)$ stoichiometries (Table S2).

In the $\mathrm{ReN}_{\mathrm{x}}$ films the nitrogen content increases with decreasing deposition temperature (Table S2). The increase in the nitrogen content is accompanied with the increase in resistivity (Figure 1a) and changes in the GIXRD patterns from hexagonal Re to other crystalline materials (Figure 1b). Reliable x-ray diffraction reference patterns for rhenium nitrides are not available, and thus the identification of the ALD grown $\operatorname{ReN}_{\mathrm{x}}$ films is limited from the 
measured GIXRD patterns. However, the two main peaks in the GIXRD pattern of the $\mathrm{Re}_{0.7} \mathrm{~N}_{0.3}$ film (N/Re ratio 0.37 ) deposited at $325^{\circ} \mathrm{C}$ could be assigned to the (111) and (200) orientations of the cubic $\mathrm{Re}_{0.69} \mathrm{~N}_{0.31}$ (N/Re ratio 0.45; 00-037-0852; "Blank" quality mark where the pattern does not meet the "Star", "Indexed", or "Low-Precision" criteria). The peak around $37^{\circ}$ could not be identified with the rhenium nitride reference XRD patterns available. Furthermore, the GIXRD pattern of the $\mathrm{Re}_{0.8} \mathrm{~N}_{0.2}$ film (N/Re ratio 0.19 ) grown at $350{ }^{\circ} \mathrm{C}$ does not show this peak, but the two peaks are close to the reference (111) and (200) orientations found in rhenium nitrides.

Surface x-ray photoelectron spectroscopy (XPS) results are presented in Tables S3 and S4. The XPS analysis corroborate the TOF-ERDA results in that at $400^{\circ} \mathrm{C}$ and above majority of the Re on the surface is at an oxidation state 0 whereas below $375^{\circ} \mathrm{C}$ other oxidation states dominate (Table S4). The transition from the rhenium nitride to metal films is also seen in the surface $N / R e$ ratios (Table S3) in line with the TOF-ERDA (Table S2) and XRD (Figure $1 \mathrm{~b}$ ) results. The film composition appears to be uniform through the film thickness as TOF-ERDA (the whole film) and XPS (the surface) give similar $\mathrm{N} / \mathrm{Re}$ ratios for the rhenium nitride films (Tables S2 and S3).

The Re ALD process was examined at $400{ }^{\circ} \mathrm{C}$ to confirm the saturative self-limiting surface reactions of both $\mathrm{ReCl}_{5}$ and $\mathrm{NH}_{3}$ precursors (Figure 2). Self-limiting growth is obtained already with very short precursor pulses of 0.2 and $0.5 \mathrm{~s}$ for $\mathrm{NH}_{3}$ and $\mathrm{ReCl}_{5}$. The film growth is also independent of the $\mathrm{NH}_{3}$ flow rate at $2 \mathrm{sccm}$ and above. The Re film grown using $0.2 \mathrm{~s} \mathrm{ReCl}_{5}$ pulses was not uniform across the substrate indicating insufficient $\mathrm{ReCl}_{5}$ dose because of the low source temperature chosen to minimize the precursor consumption. It should be emphasized that here the process is not optimized for the fastest cycle times. A bit higher source temperature should have been enough to ensure uniform film growth across the substrate also with the shortest $0.2 \mathrm{~s} \mathrm{ReCl}$ pulses. The short pulses being enough for the saturative growth indicate that this ALD process is robust which is beneficial for upscaling and commercial applications.

a)
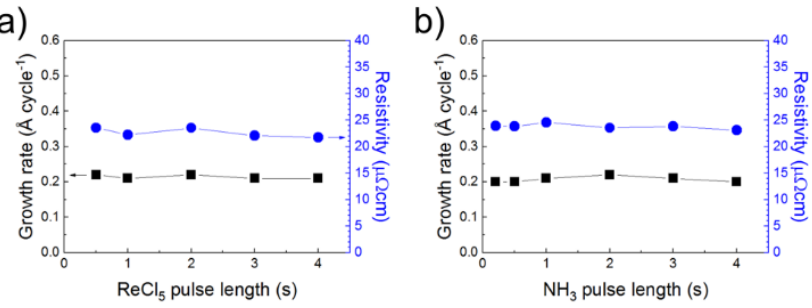

C)

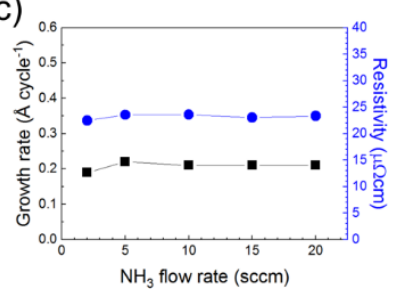
Figure 2. Re films grown on $\mathrm{Al}_{2} \mathrm{O}_{3}$ films at $400{ }^{\circ} \mathrm{C}$. Film growth rate (EDX) and
resistivity as a function of a) $\mathrm{ReCl}_{5}$ pulse length, b) $\mathrm{NH}_{3}(5 \mathrm{sccm})$ pulse length, resistivity as a function of a) $\mathrm{ReCl}_{5}$ pulse length, b) $\mathrm{NH}_{3}(5 \mathrm{sccm})$ pulse length,
c) $\mathrm{NH}_{3}$ flow rate. The total number of deposition cycles was 1000 while all the c) $\mathrm{NH}_{3}$ flow rate. The total number of deposition cycles was 1000 while all the
purges were $1 \mathrm{~s}$. In a) the $\mathrm{NH}_{3}(5 \mathrm{sccm})$ pulse length was $2 \mathrm{~s}$, in b) the $\mathrm{ReCl}_{5}$ purges were $1 \mathrm{~s}$. In a) the $\mathrm{NH}_{3}(5 \mathrm{sccm}$ ) pulse length was $2 \mathrm{~s}$,
pulse length was $2 \mathrm{~s}$, and in $\mathrm{c}$ ) both precursor pulses were $2 \mathrm{~s}$.

The film thickness follows linearly the number of deposition cycles at $400{ }^{\circ} \mathrm{C}$ (Figure 3a) and after 300 cycles metallic Re is identified in GIXRD (Figure 3b). Already a $3 \mathrm{~nm}$ thick Re film (200 cycles) is continuous and highly conductive $(\sim 90 \mu \Omega \mathrm{cm})$. The film resistivity stabilizes to about $22 \mu \Omega \mathrm{cm}$ in thicker films. The bulk resistivity of $R e$ is $18.7 \mu \Omega \mathrm{cm}$. Interestingly, one of the rhenium oxides, $\mathrm{ReO}_{3}$, possess metallic conductivity and even lower bulk resistivity $(\sim 10 \mu \Omega \mathrm{cm})$ than the metal itself. MBE grown epitaxial Re films on sapphire were reported ${ }^{[8]}$ to have resistivities of about $21 \mu \Omega \mathrm{cm}(25-100 \mathrm{~nm})$ when deposited at $700-770{ }^{\circ} \mathrm{C}$. The resistivities of the polycrystalline $\mathrm{Re}$ films grown here on amorphous $\mathrm{Al}_{2} \mathrm{O}_{3}$ stabilize close to similar resistivities as the MBE films.

a)

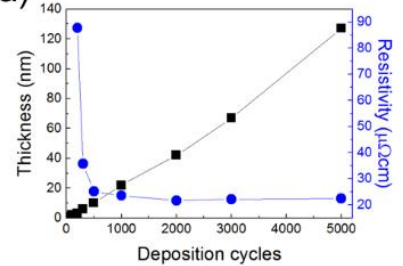

b)

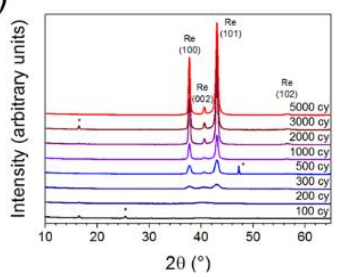

C)

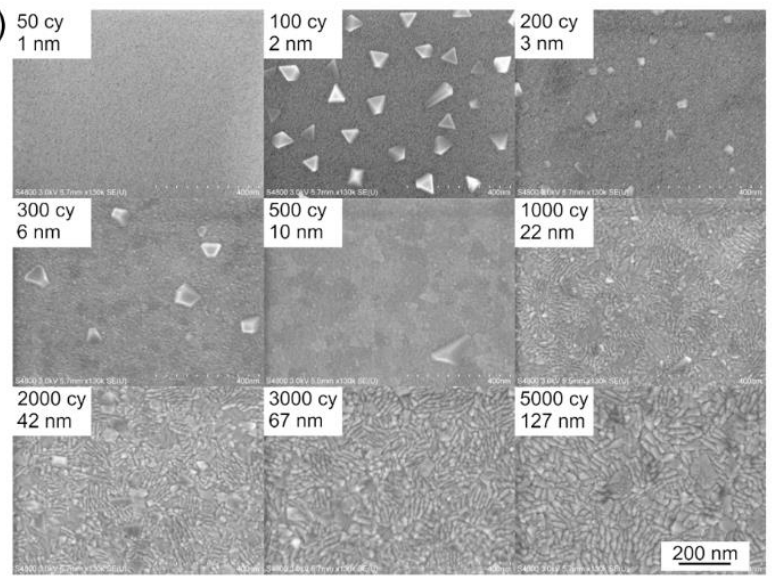
Figure 3. Re films grown on $\mathrm{Al}_{2} \mathrm{O}_{3}$ films at $400^{\circ} \mathrm{C}$ as a function of the number
of deposition cycles. a) Film thicknesses (EDX) and resistivities, b) GIXRD patterns, and c) FESEM images with the number of deposition cycles and corresponding film thicknesses. The pulse and purge lengths were $2 \mathrm{~s}$ and $1 \mathrm{~s}$, corresponding film thicknesses. The pulse and purge lengths were $2 \mathrm{~s}$ and $1 \mathrm{~s}$,
respectively. The peaks denoted by an asterisk could not be reliably identified.

The reactive nature of the thinner films under the ambient can be seen from the FESEM images (Figure 3c). The GIXRD patterns reveal the films to be nearly x-ray amorphous (Figure $3 b$ ), although the FESEM images show large crystallites on the film surface. Surfaces of amorphous Re films deposited by PLE have been noted ${ }^{[16]}$ to naturally age in air leading to the formation of $\mathrm{ReO}_{3}$. It is most probable that similar aging is occurring also here with the ALD grown Re films (Figure 4a). The aging is especially dominant on the Re films grown with a small number of deposition cycles (Figures $3 b$ and $3 c$ ) as the films were susceptible to ambient for prolonged period of time. The thicker Re films have quite distinctive crystalline surface morphology (Figure 3c). The transmission electron microscope (TEM) images reveal differences in film morphology between the $\mathrm{Re}_{0.6} \mathrm{~N}_{0.3}$ (N/Re ratio 0.48 ; stoichiometric $\mathrm{Re}_{2} \mathrm{~N}$ ratio 0.5 ) (Figure $4 \mathrm{~b}$ ) and Re metal (Figure 4a). Notably the oxidized surface layer is absent on the $\mathrm{ReN}_{\mathrm{x}}$ film indicating higher long-term stability in the ambient. The 
Re and $\mathrm{ReN}_{\mathrm{x}}$ film thicknesses determined from the TEM images are 25 and $43 \mathrm{~nm}$, respectively, which correspond well with the XRR film thicknesses (Figure 1a).

a)

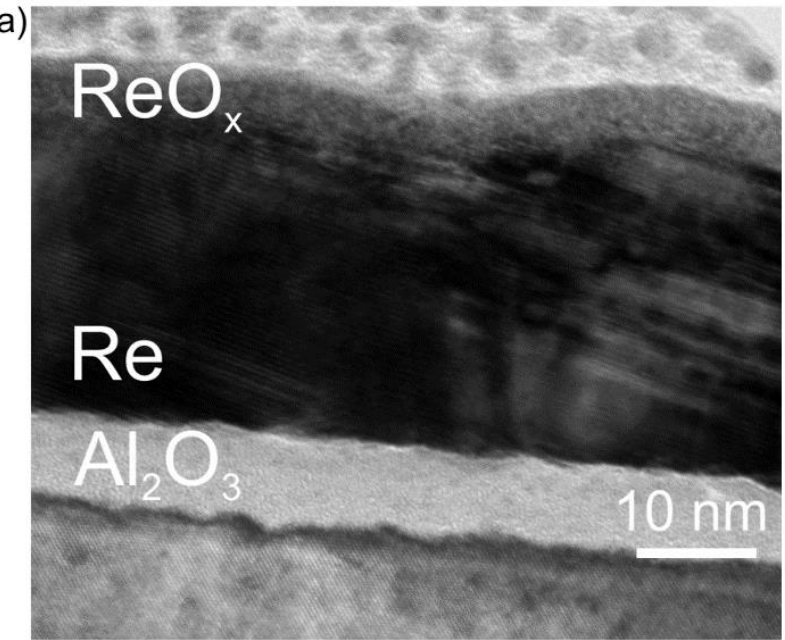

b)

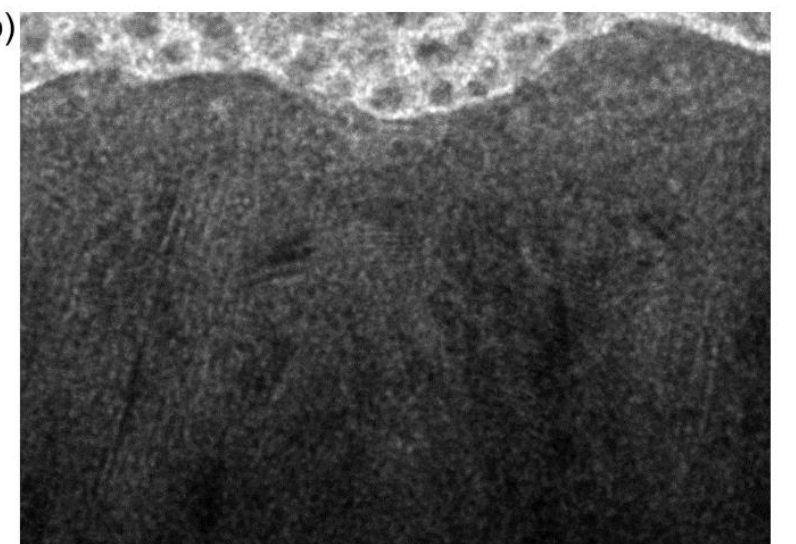

$\mathrm{ReN}_{x}$

[1] E. Scerri, Nat. Chem. 2010, 2, 598

[2] R. Kojima, K. Aika, Appl. Catal. A 2001, 209, 317-325.

[3] R. Kojima, H. Enomoto, M. Muhler, K. Aika, Appl. Catal. A 2003, 246 , 311-322.

[4] P. Clark, B. Dhandapani, S. T. Oyama, Appl. Catal. A 1999, 184, L175L180.

[5] E. Muñoz, R. Schrebler, R. Henríquez, C. Heyser, P. A. Verdugo, R. Marotti, Thin Solid Films 2009, 518, 138-146.

[6] R. Garcia-Garcia, G. Ortega-Zarzosa, M. E. Rincón, G. Orozco, Electrocatalysis 2015, 6, 263-273.

[7] W. Garrett, A. J. Sherman, J. Stiglich, Mater. Manuf. Process. 2006, 21, 618-620.

[8] E. Dumur, B. Delsol, T. Weißl, B. Kung, W. Guichard, C. Hoarau, C. Naud K. Hasselbach, O. Buisson, K. Ratter, B. Gilles, IEEE Trans. Appl. Supercond. 2016, 26, 1501304.

[9] S.-Y. Chang, L.-P. Liang, L.-C. Kao, C.-F. Lin, J. Electrochem. Soc. 2015 162, D96-D101.

[10] J. P. Chu, C. H. Lin, P. L. Sun, W.K. Leau, J. Electrochem. Soc. 2009 156, H540-H543.
Figure 4. TEM images of the a) $\mathrm{Re}$ and b) $\mathrm{ReN}_{\mathrm{x}}$ films grown at 400 and $300{ }^{\circ} \mathrm{C}$, respectively. The TEM images are from the same samples as seen in Figure 1.

To summarize, ALD was applied to deposit both $\mathrm{ReN}_{\mathrm{x}}$ and Re thin films from $\mathrm{ReCl}_{5}$ and $\mathrm{NH}_{3}$ precursors over a wide temperature range between 275 and $500{ }^{\circ} \mathrm{C}$. The films grown at $400{ }^{\circ} \mathrm{C}$ and above were Re metal whereas at lower temperatures conductive rhenium nitrides with tunable stoichiometry and resistivity (70$290 \mu \Omega \mathrm{cm}$ ) were obtained. A very thin, $3 \mathrm{~nm}$, Re film was shown to be already continuous and to have a low resistivity of about 90 $\mu \Omega \mathrm{cm}$. The resistivities of the thicker Re films were as low as 22 $\mu \Omega \mathrm{cm}$ and the amounts of impurities $(\mathrm{N}, \mathrm{H}, \mathrm{Cl}, \mathrm{C})$ were down to about 2 at. \% in total. Additionally, the Re ALD process was shown to proceed via fast surface reactions between the precursors. The simple and robust process presented here using only a metal halide and ammonia to produce conductive rheniumbased films in a highly controlled manner serves as an interesting opening to bring this intriguing element more widely available for various applications, starting with semiconductor industry.

\section{Acknowledgements}

The Finnish Center of Excellence in Atomic Layer Deposition (Academy of Finland) and academy project decision no. 309552 (Atomic Layer Deposition of Noble Metals and Their Compounds, Academy of Finland) are gratefully acknowledged for their support.

Keywords: atomic layer deposition $\cdot$ ALD $\cdot$ rhenium $•$ rhenium nitrides $\bullet$ thin films 
[11] G.-M. Xue, H.-F. Yu, Y. Tian, W.-Y. Liu, H.-W. Yu, Y.-F. Ren, S.-P. Zhao, Chin. Phys. B 2013, 22, 097401.

[12] R. P. Pezzi, M. Copel, M. Gordon, E. Cartier, I. J. R. Baumvol, Appl. Phys. Lett. 2006, 88, 243509.

[13] Z. Zhao, K. Bao, D. Li, D. Duan, F. Tian, X. Jin, C. Chen, X. Huang, B. Liu, T. Cui, Sci. Rep. 2014, 4, 4797.

[14] Y. Liang, X. Yuan, W. Zhang, J. Appl. Phys. 2011, 109, 053501.

[15] H. C. King, M. C. Renier, K. E. Ellzey, W. J. Lackey, Chem. Vap. Deposition 2003, 9, 59-63.

[16] A. G. Bagmut, I. A. Bagmut, T. K. Murav'ev, D. V. Slabokrug, Funct. Mater. 2013, 20, 180-185.

[17] K. H. Cho, U. Patel, J. Podkaminer, Y. Gao, C. M. Folkman, C. W. Bark S. Lee, Y. Zhang, X. Q. Pan, R. McDermott, C. B. Eom, APL Mater. 2013, $1,042115$.

[18] G. Soto, H. Tiznado, A. Reyes, W. de la Cruz, J. Alloys Compd. 2012, $514,127-134$
[19] G. Soto, H. Tiznado, W. de la Cruz, A. Reyes, J. Mater. 2014, 2014, 745736.

[20] A ul. Haq, O. Meyer, J. Low Temp. Phys. 1983, 50, 123-133.

[21] M. Fuchigami, K. Inumaru, S. Yamanaka, J. Alloys Compd. 2009, 486, 621-627.

[22] L. Lei, W. Yin, X. Jiang, S. Lin, D. He, Inorg. Chem. 2013, 52, 1335613362.

[23] L. Qi, L. Lei, Q. Hu, L. Zhang, L. Feng, M. Pu, H. Ohfuji, J. Appl. Phys. 2018, 123, 055901.

[24] M. Leskelä, M. Ritala, Angew. Chem. Int. Ed. 2003, 42, 5548-5554.

[25] V. Miikkulainen, M. Leskelä, M. Ritala, R. L. Puurunen, J. Appl. Phys. 2013, 113, 021301.

[26] J. Hämäläinen, M. Mattinen, K. Mizohata, K. Meinander, M. Vehkamäki, J. Räisänen, M. Ritala, M. Leskelä, Adv. Mater. 2018, 30, 1703622.

[27] A.-M. Alexander, J. S. J. Hargreaves, C. Mitchell, Top. Catal. 2013, 56 1963-1969. 


\section{COMMUNICATION}

Highly conductive rhenium and rhenium nitride thin films are deposited at moderate temperatures. The films grow in a highly controllable manner from ammonia and rhenium pentachloride at temperatures up to $500{ }^{\circ} \mathrm{C}$ by atomic layer deposition. As thin as $3 \mathrm{~nm}$ rhenium film is already continuous and has a low resistivity of $90 \mu \Omega \mathrm{cm}$.

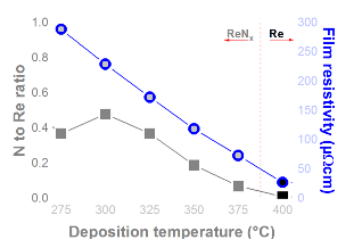

Jani Hämäläinen*, Kenichiro Mizohata, Kristoffer Meinander, Miika Mattinen, Marko Vehkamäki, Jyrki Räisänen, Mikko Ritala, Markku Leskelä

Page No. - Page No.

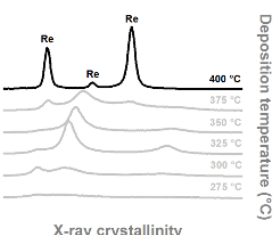

Rhenium Metal and Rhenium Nitride Thin Films Grown by Atomic Layer Deposition 